\title{
Negative urgency partially accounts for the relationship between major depressive disorder and marijuana problems
}

\author{
Rachel L. Gunn ${ }^{1}$, Kristina M. Jackson ${ }^{1}$, Brian Borsari ${ }^{2,3}$ and Jane Metrik ${ }^{1, *^{*}}$
}

\begin{abstract}
Background: To goal of this study was to better understand mechanisms underlying associations between Major Depressive Disorder (MDD) and marijuana use and problems. Specifically, it was hypothesized that negative urgency $(\mathrm{NU})$, the tendency to act rashly while experiencing negative mood states, would uniquely (compared to other impulsivity traits: positive urgency, sensation seeking, premeditation, and perseverance) account for the relationship between MDD and marijuana use and problems.

Methods: Data were collected from a sample $(N=357)$ of veterans $(M$ age $=33.63)$ recruited from a Veterans Affairs hospital who used marijuana at least once in their lifetime. Participants completed the SCID-NP to assess MDD, a marijuana problems scale, a Time-Line Follow-back to assess six-month marijuana use, and the UPPS-P Impulsive Behavior Scale for impulsivity.

Results: Path analysis was conducted using bootstrapped $(k=20,000)$ and bias-corrected $95 \%$ confidence intervals (Cls) to estimate mediation (indirect) effects, controlling for age, sex, and race. Analyses revealed a significant direct effect of MDD on NU and NU on marijuana problems. Regarding mediational analyses, there was a significant indirect effect of MDD on marijuana problems via NU. The direct effect of MDD on marijuana problems was reduced, but remained significant, suggesting partial mediation. No other impulsivity scales accounted for the relationship between MDD and marijuana problems. In predicting marijuana use, there were no significant indirect effects for any impulsivity traits, including NU, despite significant bivariate associations between use and NU and MDD.

Conclusions: Results suggest that high levels of NU may partially explain associations between MDD and marijuana problems, but not marijuana use. No other facets of impulsivity accounted for the relationship between MDD and marijuana use or problems, underscoring the specificity of $\mathrm{NU}$ as a putative mechanism and the importance of assessing $\mathrm{NU}$ in treatment settings.
\end{abstract}

Keywords: Marijuana problems, Cannabis, Negative urgency, Depression, Major depressive disorder, UPPS-P

\section{Background}

Marijuana is the most commonly used illicit drug worldwide [1], with the majority of US states having legalized it for either recreational and/or medicinal use within the past decade. In the wake of these rapid social and legal changes, epidemiological research reveals that past-year cannabis use disorder (CUD) rates have increased in the general population [2] and have also more than doubled

\footnotetext{
* Correspondence: jane_metrik@brown.edu

${ }^{1}$ Center for Alcohol and Addiction Studies, Brown University School of Public Health, Providence, RI 02903, USA

${ }^{4}$ Providence VA Medical Center, Providence, RI 02908, USA

Full list of author information is available at the end of the article
}

in the past decade among military veterans [3]. Among individuals with CUD (and other substance use disorders), rates of comorbid mood disorders are higher relative to those without CUD [2, 4, 5]. Comorbidity between mood disorders and SUDs including CUD is particularly common in veterans $[6,7]$, particularly postdeployment [8], calling for more research investigating potential mechanisms to explain this comorbidity.

\section{Major depressive disorder and marijuana use}

Major Depressive Disorder (MDD) is one psychiatric disorder shown to be strongly associated with both CUD and 
marijuana problems in general populations [4, 9-13] and among veterans $[5,14]$. Affective-motivational theory emphasizes the central role of negative affect in motivating drug use, including marijuana use specifically $[15,16]$. Recent cross-sectional data suggest that marijuana users who experience MDD are more likely to have CUD than marijuana users without MDD [12]. Cross-sectional between-subject $[5,17]$ and prospective within-subject [18] empirical research in support of this theory suggests that greater intensity of negative affect associated with MDD leads to increased marijuana use to in order to cope with negative emotions. Yet, coping-oriented use of substances has also been shown to worsen affective symptoms of depression and to increase substance misuse $[19,20]$.

Evidence for the directionality of the association between MDD and CUD is mixed. Some longitudinal studies have provided evidence that cannabis use predicted increased symptoms of depression; whereas depressive symptoms did not predict increased cannabis use [21, 22]. However, this directionality was only found among adolescent girls in one study, limiting generalizability [22]. One meta-analysis of longitudinal studies found that heavy cannabis use may be associated with increased depressive symptoms, but did not explore the opposite direction (depressive symptoms to CUD [23]). In contrast, large epidemiological studies have also revealed MDD was prospectively associated with CUD and contributed to its etiology [24, 25]. Additional longitudinal work has suggested a bidirectional relationship between depressive symptoms and cannabis use from adolescence to young adulthood across five years of assessment in men [26].

\section{Impulsivity and marijuana use and problems}

Impulsive personality traits have long been a hallmark characteristic for substance misuse and substance use disorders in general [27-29]. Certain facets of impulsivity, such as delay discounting, have been associated with greater marijuana use [30] and marijuana dependence [31]. Composite scores of attentional, motor, and nonplanning impulsivity have also been associated with marijuana problems [32, 33]. Importantly, the UPPS-P Impulsive Behaviors Scale [34] classifies impulsivity as multi-faceted construct $[35,36]$, in which certain traits are uniquely related to specific risky behaviors [37-40]. Each of these five impulsivity-like traits (negative urgency, positive urgency, sensation seeking, lack of premeditation, and lack of perseverance) have been found to be associated with marijuana use and related consequences [15, 41-43].

Impulsivity, major depressive disorder, and marijuana use and problems

Impulsive personality traits may partially explain the association between MDD and marijuana use and problems. Specifically, negative urgency (NU), one facet of impulsivity characterized by rash action when experiencing emotional distress [36], may be of particular relevance to this comorbidity. When considering all facets of the UPPS-P model, $\mathrm{NU}$ and lack of perseverance specifically have been shown to relate to symptoms of MDD [44, 45]. NU has also been associated with marijuana use and problems in general populations $[42,46]$. Relatedly, NU has been associated with alcohol use problems, particularly among those with higher levels of MDD [44, 47]. It may be that MDD places individuals at risk for marijuana problems via a similar mechanism. Thus, marijuana users with MDD may be more likely to act without thinking when upset or distressed. This in turn may lead to heavier use and a greater number of negative consequences related to marijuana use.

\section{The present study}

In order to clarify the mechanisms linking MDD and problematic marijuana use, this study sought to examine whether NU would uniquely (compared to other impulsivity traits) explain the relationship between MDD and marijuana use and problems. Two specific questions are examined: 1) The extent to which higher NU accounts for the relationship between MDD and marijuana use and problems; and 2) Whether this effect is unique to NU, or if other impulsive personality traits also partially account for the relationship between MDD and marijuana use and problems.

\section{Methods}

\section{Sample and procedure}

Data were drawn from a larger prospective study examining marijuana use and affective disorders in returning Operation Enduring Freedom, Operation Iraqi Freedom, and Operation New Dawn (OEF/OIF/OND) veterans who were deployed post 9/11/2001 and who used marijuana at least once in his/her lifetime. Participants were recruited from a VHA facility in the Northeast US by utilizing the VHA OEF/OIF/OND Roster, an accruing database of combat veterans who have recently returned from military service in Iraq and Afghanistan and enrolled in VHA (see Metrik et al., 2016, for details of recruitment procedures). Veterans were screened for eligibility by telephone and were invited for a baseline visit, at which time they signed informed consent and completed a battery of interview and self-report assessments (including all measures analyzed in the current study). The study was approved by the university and local VHA Institutional Review Boards. Participants were compensated $\$ 50$ upon completion of the study session. The original sample included 361 participants, from which four subjects were removed for missing data, resulting in a final $N=357$. 


\section{Measures \\ Structured clinical interview for DSM, non-patient edition (SCID-NP)}

Was used to determine DSM-5 [48] diagnosis of current (past month) Major Depressive Disorder [49]. All SCID interviews were administered by research assistants, who were trained by the PI and required to demonstrate adherence and competence to the interview. All SCIDs were audiotaped and a random selection of the recordings ( $n=72,20 \%)$ were later rated by an independent doctoratelevel clinician, resulting in excellent inter-rater reliability (ICC = .98-.99, 95\%, CIs [.96-.99]). Any discrepancies were resolved in discussion with the PIs (BB and JM).

\section{Marijuana problems}

Marijuana-related problems were assessed with the Marijuana Problems Scale (MPS; [50]), a self-report 22item questionnaire that evaluates problems experienced in the past 90 days related to marijuana use. A total count of combined minor and serious problems was used rather than a severity score. The MPS has strong internal consistency in previous studies $[50,51]$ and in this sample $(\alpha=.91)$.

\section{Marijuana use}

The Time-Line Follow-Back Interview (TLFB; $[52,53]$ ) was used to record percent days of marijuana use over the six months prior to the visit.

\section{Impulsive personality traits}

Facets of impulsivity were assessed using the Short UPPSP Impulsive Behavior Scale [54]. The UPPS-P is a 20-item self-report inventory which uses a 4-point likert scale to assesses five subscales of impulsive personality (negative urgency $[\mathrm{NU}]$, positive urgency $[\mathrm{PU}]$, sensation seeking [SS], lack of premeditation [PM], and lack of perseverance [PS]), each demonstrating high levels of internal consistency in previous studies [54]. These subscales demonstrated acceptable (PS $\alpha=.69$, SS $\alpha=.62$ ) to good (NU $\alpha=.77$, PU $\alpha=.83$, PM $\alpha=.82$ ) internal consistency.

\section{Data analytic strategy}

Descriptive statistics and bivariate (point biseral for dichotomous variables) correlations were first examined. Next, hypothesized mediational models were examined. MDD was specified as the predictor, or independent variable; marijuana use and problems were specified as the outcomes, and impulsivity measures were specified as the mediators of interest. Several studies show that the several facets of the UPPS-P model of impulsivity are highly intercorrelated [40,55]. Including all five traits in a single model can create statistical suppression and make it difficult to interpret each unique effect [56]. In order to address this issue, we first examined the correlations between each trait to guide decisions for which traits to examine for mediation. Specifically, we examined Negative Urgency [NU], Positive Urgency [PU], and Lack of Perseverance [PS] because, as reported below, they were significantly associated with both MDD and marijuana outcomes in this sample. A total of eight mediational models were tested. First, we tested separate models for each of the marijuana outcomes (marijuana problems and percent marijuana use days from the TLFB), for each of the mediators (NU, PU, and PS), which resulted in a total of six models. Then, we tested two models with all mediators entered simultaneously in order to examine whether any significant associations remained. Finally, given the cross-sectional nature of the data, followup mediation analyses with reverse directionality were tested, where marijuana use and problems were specified as the predictor, or independent variable; MDD was specified as the outcome, with impulsivity measures remaining as mediators of interest.

The primary data analyses were a structural equation model (SEM) with maximum likelihood estimation to using AMOS 24.0 [57]. All models regressed the dependent variable (marijuana problems or use) onto covariates (age [continuous], sex [binary], and race [binary, non-Hispanic Caucasian]). Covariates were allowed to correlate with each other in single and multiple mediator models. In order to estimate mediation effects, bootstrapped $(k=20,000)$ and bias-corrected $95 \%$ confidence intervals (CIs) were estimated for the indirect effects [58]. Mediation is tested by examining the direct, indirect, and total effects. Significant mediation effects are apparent when indirect effects are significant and total effects are reduced in the presence of the mediator. To assess the degree to which the structural models fit the sample variance-covariance data, two criteria of model fit were relied upon: the Comparative Fit Index (CFI: [59]), and the root-mean- square error of residual approximation (RMSEA: [60]). Although guidelines for good fit vary, values above .90 for CFI and below .05 for RMSEA are considered acceptable [61].

\section{Results \\ Descriptive statistics and bivariate correlations}

Table 1 presents sample demographics and substance use descriptive statistics. Table 2 presents bivariate correlations. As expected, MDD was positively associated with marijuana use and marijuana problems. Also as expected, MDD was positively associated with NU. Additionally, MDD was associated with PU, and PS, and PM. In this sample, marijuana problems were positively associated with NU, PU, and PS. Marijuana use was also associated with NU, PU, PS, as well as PM.

\section{Mediation models}

A set of mediation models for each of the two outcomes were first tested. We did not examine mediation by SS 
Table 1 Descriptive Statistics

\begin{tabular}{|c|c|c|}
\hline Variable & $n$ & $\%$ \\
\hline Sex (Male) & 335 & 94 \\
\hline \multicolumn{3}{|l|}{ Race } \\
\hline White & 286 & 80 \\
\hline Black/African American & 16 & 4 \\
\hline Asian & 6 & 2 \\
\hline Native Hawaiian/Pacific Islander & 2 & 01 \\
\hline American Indian/Alaska Native & 2 & 01 \\
\hline Multiracial/Other & 25 & 8 \\
\hline \multicolumn{3}{|l|}{ Ethnicity } \\
\hline Hispanic/Latino(a) & 88 & 25 \\
\hline \multicolumn{3}{|l|}{ Marital Status } \\
\hline Single/Never Married & 115 & 32 \\
\hline Married/Living with Partner & 170 & 48 \\
\hline Divorced/Separated & 72 & 20 \\
\hline \multicolumn{3}{|l|}{ Employment Status } \\
\hline Employed & 279 & 78 \\
\hline Unemployed & 123 & 34 \\
\hline Student & 27 & 8 \\
\hline Military service & 100 & 28 \\
\hline \multicolumn{3}{|l|}{ DSM-5 Diagnoses } \\
\hline Cannabis Use Disorder, current & 52 & 15 \\
\hline Cannabis Use Disorder, lifetime & 132 & 37 \\
\hline \multirow[t]{2}{*}{ Major Depressive Disorder } & 53 & 15 \\
\hline & M & SD \\
\hline Age & 33.63 & 9.46 \\
\hline Years of Education & 13.72 & 2.12 \\
\hline
\end{tabular}

$N=357$; Employment Status: participants were instructed to 'check all that apply' regarding their employment status over the past year or PM due to lack of association with MDD (SS) and marijuana use (SS) and problems (SS and PM). Results are presented in Table 3, the top portion of which presents effects for single mediator models and the bottom portion for multiple mediator models.

\section{Marijuana use}

In predicting marijuana use frequency, single mediator models did not return significant indirect effects for NU, PU or PS, indicating they did not account for the association between MDD and marijuana use. In the multiple mediator model, there was a significant indirect effect of MDD on marijuana use $(\beta=.03, p<.05,95 \%$ CI $[.01$, $.09]$ ), however none of the proposed mediators accounted for this indirect effect (see Table 3). Age was the only variable with a significant direct effect on marijuana use $(\beta=-.16, p<.001)$, while NU, PU, and PS remained non-significant (see bottom panel of Table 3). Results were consistent in the mediation model with reverse directionality, as there were no indirect effects of MDD on marijuana use.

\section{Marijuana problems}

In separate single mediator models examining the association between MDD and marijuana problems, there was a significant indirect effect of NU, as hypothesized (see top panel of Table 3). This model suggested that NU significantly accounted for the relationship between MDD and marijuana problems (see Fig. 1). As can be seen in Fig. 1, a significant direct effect of MDD on marijuana problems remained when $\mathrm{NU}$ was in the model, suggesting partial mediation. As can also be seen in the model, there was a significant direct effect of MDD on NU and NU on marijuana problems. This model fit adequately, $X^{2}(6)=11.84, p=.07, \mathrm{CFI}=.91$, $\mathrm{NFI}=.85$, RMSEA $=.05$. As expected, neither PU nor PS

Table 2 Bivariate Correlations

\begin{tabular}{|c|c|c|c|c|c|c|c|c|c|c|c|c|}
\hline Variable & 1. & 2. & 3. & 4. & 5. & 6. & 7. & 8. & 9. & 10. & 11. & $M(s d)$ \\
\hline 1. MJ problems & - & $.37^{* * *}$ & $.14^{* *}$ & $.21^{* * *}$ & .05 & $.13^{*}$ & .02 & $.21^{* * *}$ & -.10 & .01 & -.10 & $1.07(2.71)$ \\
\hline 2. MJ use & & - & $.12^{*}$ & $.17^{* *}$ & .04 & $.13^{*}$ & $.11^{*}$ & $.26^{* * *}$ & $-.18^{* *}$ & .07 & -.01 & $16.13(32.7)$ \\
\hline 3. PU & & & - & $.56^{* * *}$ & $.19^{* * *}$ & $.15^{* *}$ & $.42^{* * *}$ & $.19^{* * *}$ & $-.16^{* *}$ & $-.14^{* *}$ & -.10 & $2.16(.72)$ \\
\hline 4. NU & & & & - & -.01 & $.21 * * *$ & $.43^{* * *}$ & $.29^{* * *}$ & -.08 & .01 & .01 & $1.75(.67)$ \\
\hline 5. SS & & & & & - & -.10 & .07 & -.07 & $-.21^{* *}$ & $-.19^{* *}$ & -.00 & $2.88(.69)$ \\
\hline 6. PS & & & & & & - & $.41^{* * *}$ & $.16^{* *}$ & -.08 & .05 & -.05 & $1.61(.49)$ \\
\hline 7. PM & & & & & & & - & $.23^{* * *}$ & $-.14^{* *}$ & -.00 & .03 & $1.76(.56)$ \\
\hline 8. MDD & & & & & & & & - & -.02 & $-.16^{* *}$ & .04 & $-^{a}$ \\
\hline 9. Age & & & & & & & & & - & -.01 & .08 & $-{ }^{a}$ \\
\hline 10. Sex & & & & & & & & & & - & -.02 & $--^{a}$ \\
\hline 11. Race & & & & & & & & & & & - & $-{ }^{\mathrm{a}}$ \\
\hline
\end{tabular}

MJ Marijuana problems, MJ use \% Marijuana use days, $P U$ positive urgency, NU negative urgency, SS sensation seeking, $P S$ lack of perseverance, $P M$ lack of premeditation, MDD Major Depressive Disorder. ${ }^{* * *} p<.001,{ }^{* *} p<.01,{ }^{*} p<.05$; ${ }^{a}$ Mean and standard deviation not presented due to dichotomous variable, Table 1 presents appropriate descriptive statistics for these variables 
Table 3 Results of Path models: Indirect and Direct effects of MDD on Marijuana Use and Problems, via Impulsive Personality Traits

\begin{tabular}{|c|c|c|c|}
\hline & $\begin{array}{l}\text { Direct path to mediator } \\
\text { (a path) }\end{array}$ & $\begin{array}{l}\text { Marijuana Use } \\
\text { (b path) }\end{array}$ & $\begin{array}{l}\text { Marijuana Problems } \\
\text { (b path) }\end{array}$ \\
\hline Mediator & $B(S E)$ & $B(S E)$ & $B(S E)$ \\
\hline
\end{tabular}

Single Mediator Models

Direct Effect

$\begin{array}{llll}\text { NU } & .29(05)^{* * *} & .09(.05) & .15(.06)^{*} \\ \text { PU } & .21(.06)^{* * *} & .06(.05) & .08(.08) \\ \text { PS } & .15(.06)^{* *} & .08(.06) & .09(.05)\end{array}$

Indirect Effect

$\begin{array}{lll}\text { NU } & .03(.02) & .05(.02)^{*} \\ \text { PU } & .01(.01) & .02(.02) \\ \text { PS } & .01(.01) & .01(.01)\end{array}$

Multiple Mediator Model

Direct Effect

$\begin{array}{llll}\mathrm{NU} & .29(.05)^{* * *} & .07(.06) & .15(.07)^{*} \\ \mathrm{PU} & .19(.06)^{* * *} & .01(.06) & -.01(.07) \\ \mathrm{PS} & .16(.06)^{* *} & .06(.06) & .07(.06)\end{array}$

Indirect Effect $(\mathrm{a} \times \mathrm{b})$

$.03(.02)^{*} \quad .05(.02)^{*}$

Total Effect

$$
.25(.07)^{* * *} \quad .22(.07)^{* * *}
$$

$N U$ negative urgency, $P U$ positive urgency, $P S$ lack of perseverance, MDD Major Depressive Disorder. Parameters are standardized. All models control for age, sex, and race. ${ }^{* * *} p<.001,{ }^{* *} p<.01,{ }^{*} p<.05$

accounted for the relationship between MDD and marijuana problems in single mediator models (see top panel, Table 3). In the mediation model with reverse directionality, examining the association between marijuana problems and MDD, there were significant total effects $(\beta=.22, p=.001)$, direct effects $(\beta=.16$, $p=.01)$, and indirect effects $(\beta=.05, p<.01,95 \% \mathrm{CI}$

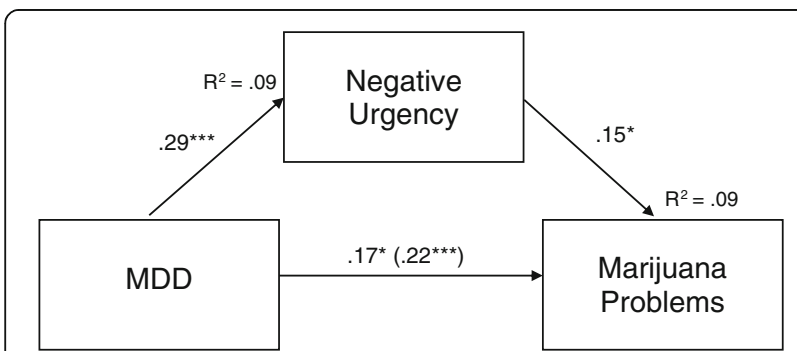

Fig. $1 \mathrm{NU}$ partially accounts for the association between MDD and Marijuana Problems Note. Parameter estimates are from the single mediator model. Mediational path model of the association between MDD, NU, and marijuana problems. Single directional arrows represent standard regression weights. The direct effect of MDD on marijuana problems before $\mathrm{NU}$ was included in the model is presented in parentheses. Models controlled for age, sex, and race. ${ }^{* * *} p<.001$, ${ }^{*} p<.01,{ }^{*} p<.05$
$[.02, .09])$ of MDD on marijuana problems, providing comparable evidence for partial mediation.

In the multiple mediator model, the indirect effect of NU remained significant when PU and PS were still in the model, suggesting it significantly accounted for the association between MDD and marijuana problems (see bottom panel of Table 3 ). This model fit adequately, $\chi^{2}$ $(12)=38.53, p<.001, \mathrm{CFI}=.88, \mathrm{NFI}=.85$, RMSEA $=.08$, and revealed significant total effects, direct effects, and indirect effects of MDD on marijuana problems providing evidence for partial mediation (see bottom panel of Table 3). Consistent with the single mediator model, the reverse multiple mediator model also found significant total effects $(\beta=.22, p=.001)$, direct effects $(\beta=.16, p=.01)$, and indirect effects $(\beta=.06, p<.01$, $95 \% \mathrm{CI}[.02, .11])$ of MDD on marijuana problems providing comparable evidence for partial mediation.

\section{Discussion}

The goal of the present study was to better understand mechanisms associated with high rates of co-occurring MDD and problematic marijuana use by examining the role of specific facets of the UPPS-P model of impulsive personality $[35,36]$ in this comorbidity. To our knowledge, the current study is the first to systematically examine the role of these personality traits between MDD and marijuana use and problems. As hypothesized, we found that NU partially accounted for the relationship between MDD and marijuana problems, but this was not true of the other impulsivity traits.

Consistent with previous research $[5,9]$, we found that MDD was associated with marijuana use and problems. Although this is not the first study to examine the relationship between MDD and marijuana use and problems, it is the first to examine how individual dispositions to impulsive/rash action may help explain the association between these two clinical problems. We were also able to replicate previous research suggesting an association between MDD and NU [44, 45]. The current study expands this literature by suggesting that individuals with MDD and high levels of NU are in turn more likely to have greater number of marijuana problems. Importantly, our results also suggest that NU is the only trait in the UPPS model that accounted for the association between MDD and marijuana problems. This is consistent with theory suggesting the increased negative affect experienced by those with mood disorder, such as MDD, may lead to increased substance-related problems [15]. This high rate of negative affect may be particularly problematic for individuals also high in NU, who may in turn be more likely to act impulsively when experiencing negative mood states, and thus be more likely to experience problems related to substance use. Although results in support of this mediational pathway are compelling, remaining variance in our 
models suggest alternative pathways may exist to explain this comorbidity. For example, marijuana coping motives have also been shown to mediate the relationship between MDD or other affective vulnerabilities, such as anxiety and distress tolerance, and marijuana use and problems in general and veteran populations [5, 13, 62-64].

Contrary to our hypothesis, this mediational pathway was not present for marijuana use, indicating that $\mathrm{NU}$ is specifically implicated in the experience of problematic marijuana use. This is consistent with work suggesting that NU is a robust predictor of both marijuana problems [41, 65] and alcohol problems [66-68], although the relationship between NU and marijuana problems has received far less attention. Previous studies have used similar methods to explain the relationship between MDD and alcohol use and problems. In one study of young adult drinkers, NU significantly mediated the relationship between depressive symptoms and alcohol problems when controlling for alcohol use [47]. Similarly, King and colleagues [67] examined which of the UPPS-P model traits might moderate the relationship between depressive symptoms and alcohol problems among college student drinkers. They found that although NU was the strongest predictor of alcohol problems, lack of premeditation was the only moderator of depressive symptoms and alcohol problems. Although this study examined impulsivity traits as moderators, it is important to mention as they found unique associations between $\mathrm{NU}$ and depressive symptoms when examining alcohol problems, which is consistent with our findings with marijuana problems.

The present study expands this knowledge by not only showing that the relationship between MDD and marijuana problems may be partially explained by NU, but also in a population of military veterans. Veterans often have higher rates of MDD and substance use disorders including CUD compared to the general population $[69,70]$, and thus an important target population for intervention. The present research has important treatment and prevention implications for individuals with MDD and marijuana problems. Given the emerging evidence of an association between NU and marijuana problems in a number of different populations, it may be important for clinicians to assess for NU to be aware of the additional risk for those with MDD and high levels of NU. Although we focused on the directional pathway of MDD predicting marijuana-related behvaiors, it is also important to acknowledge that longitudinal evidence also exists to suggest that marijuana use is prospectively associated with depressive symptoms and other mood disorders [see review: 16]. Therefore, individuals at risk for depression and those with MDD should consider avoiding using marijuana, as it could in turn exacerbate the severity of depressive symptoms.

\section{Limitations and conclusions}

A few limitations should be considered when interpreting the results of this study. First, our data are cross-sectional and cannot provide a test of the model that MDD leads to higher levels of NU, and in turn increased marijuana problems. It is possible that greater predisposition to NU precedes the development of both MDD and marijuana problems. There also appears to be support for bidirectionality in the effects, such that marijuana problems and use could also lead to or exacerbate symptoms of MDD. In fact, we tested both directional pathways with the mediation analyses and found consistent results, suggesting this is likely a bidirectional relationship, and that NU may be a consistent mediator for both pathways to comorbidity. Future prospective modeling is needed to directly empirically evaluate the extent to which depression may further maintain problematic patterns of marijuana use and to clarify the role of NU. Second, the timeframes by which the measures are assessed vary. MDD was assessed over the past month, and marijuana use and problems over longer timeframes (six and three months, respectively), further limiting any conclusions about directionality. However, regardless of the inability of the present study to resolve directionality, we believe it still sheds important light on the mechanisms linking MDD and problematic marijuana use.

Third, the use of a veteran population meant there was a very small number of women in the sample, (although the proportion in this study was representative of the 5$10 \%$ of women among U.S. military veterans). This limits the generalizability to women in non-veteran populations. Fourth, the use of frequency over quantity of marijuana use in the TLFB may have reduced the likelihood of finding an association with $\mathrm{NU}$, as quantity may me a more sensitive test of problematic use compared to frequency. Additionally, relevant to the TLFB, is the length of the assessment window (6 months), which may be increasingly subject to retrospective recall bias when compared to shorter time periods. Although research suggests that TLFB reports underestimate frequency and quantity, this recall is not temporally biased. In other words, reports do not change significantly across time period (from 30 to 60 to 366 days [71]; 30 and 180-day intervals [72]).

Despite these limitations, the findings presented here provide important information about the risk for problematic marijuana use among individuals with co-occurring depressive symptoms, and the role of high levels of NU. Moreover, they suggest that relative to other common impulsive personality traits, individuals high in NU are at particular risk for problems related to their marijuana use. Future studies would benefit from studying these associations longitudinally and with a more diverse sample of both men and women in order to determine possible causality between MDD, NU, and problematic marijuana use. 


\section{Abbreviations}

MDD: Major Depressive Disorder; NU: negative urgency; PM: lack of premeditation; PS: lack of perseverance; PU: positive urgency; SS: sensation seeking

\section{Acknowledgements}

The authors gratefully acknowledge Cassandra Delapaix, Rebecca Swagger, Madeline Benz, Hannah Wheeler, Suzanne Sales, and Julie Evon for their contribution to the project.

\section{Funding}

National Institute on Drug Abuse grant (R01 DA033425), awarded to Jane Metrik and Brian Borsari; National Institute on Alcohol Abuse and Alcoholism Training Grant to Rachel Gunn (T32 AA007459, PI: Monti), and National Institute on Alcohol Abuse and Alcoholism K02 AA13938 (PI: Jackson).

\section{Availability of data and materials}

The datasets generated and/or analyzed during the current study are not yet publicly available due to the main outcomes of the parent study still in the process of data analysis and preparation for publication. Data will be available from the corresponding author on reasonable request upon the dissemination of primary outcome findings from the parent grant.

\section{Authors' contributions}

$\mathrm{JM}$ and BB designed the project that collected the data for the current study. RG conducted literature search and analyzed and interpreted the data with guidance from JM and KJ. RG wrote the first draft of the manuscript with significant contribution from all authors, who have approved the final manuscript.

\section{Ethics approval and consent to participate}

This research was conducted following the ethical guidelines set forth in accordance with the Declaration of Helsinki and the project has been reviewed and approved by the Institutional Review Boards at the Providence VA Medical Center and at Brown University. All subjects provided informed consent.

\section{Competing interests}

The authors declare that they have no competing interests.

\section{Publisher's Note}

Springer Nature remains neutral with regard to jurisdictional claims in published maps and institutional affiliations.

\section{Author details}

${ }^{1}$ Center for Alcohol and Addiction Studies, Brown University School of Public Health, Providence, RI 02903, USA. San Francisco VA Medical Center, San Francisco, California 94121, USA. ${ }^{3}$ University of California, San Francisco 94143, USA. ${ }^{4}$ Providence VA Medical Center, Providence, RI 02908, USA.

Received: 19 February 2018 Accepted: 1 May 2018

Published online: 16 May 2018

\section{References}

1. Center for Behavioral Health Statistics and Quality. (2016). Key substance use and mental health indicators in the United States: Results from the 2015 National Survey on Drug Use and Health (HHS Publication No. SMA 164984, NSDUH Series H-51). Retrieved from http://www.samhsa.gov/data/.

2. Grant BF, Saha TD, Ruan WJ, Goldstein RB, Chou SP, Jung J, et al. Epidemiology of DSM-5 drug use disorder: results from the National Epidemiologic Survey on alcohol and related conditions-III Bridget. JAMA Psychiatry. 2016;73:39.

3. Bonn-Miller MO, Harris AHS, Trafton JA. Prevalence of cannabis use disorder diagnoses among veterans in 2002, 2008, and 2009. Psychol Serv. 2012;9 404-16.

4. Chen C-Y, Wagner FA, Anthony JC. Marijuana use and the risk of major depressive episode epidemiological evidence from the United States National Comorbidity Survey. Soc Psychiatry Psychiatr Epidemiol. 2002;37: 199-206.

5. Metrik J, Jackson K, Bassett SS, Zvolensky MJ, Seal K, Borsari B. The mediating roles of coping, sleep, and anxiety motives in cannabis use and problems among returning veterans with PTSD and MDD. Psychol Addict Behav. 2016 30:743-54.

6. Seal KH, Metzler TJ, Gima KS, Bertenthal D, Maguen S, Marmar CR. Trends and risk factors for mental health diagnoses among Iraq and Afghanistan veterans using Department of Veterans Affairs Health Care, 2002-2008. Am J Public Health. 2009:99:1651-8.

7. Teeters JB, Lancaster CL, Brown DG, Back SE. Substance use disorders in military veterans: prevalence and treatment challenges. Subst Abuse Rehabil. 2017:8:69-77.

8. Hoge CW, Auchterlonie JL, Milliken CS. Mental health problems, use of mental health services, and attrition from military service after returning from deployment to Iraq or Afghanistan. JAMA. 2006;295:1023-32.

9. Degenhardt L, Hall W, Lynskey M. Exploring the association between cannabis use and depression. Addiction. 2003;98:1493-504.

10. Feingold D, Fox J, Rehm J, Lev-Ran S. Natural outcome of cannabis use disorder: a 3-year longitudinal follow-up. Addiction. 2015;110:1963-74.

11. Grant BF. Prevalence and co-occurrence of substance use disorders and independent mood and anxiety disorders on alcohol and related conditions. Arch Gen Psychiatry. 2004;61:807-16.

12. Dierker L, Selya A, Lanza S, Li R, Rose J. Depression and marijuana use disorder symptoms among current marijuana users. Addict Behav. 2018;76: $161-8$.

13. Farris SG, Metrik J, Bonn-Miller MO, Kahler CW, Zvolensky MJ. Anxiety sensitivity and distress intolerance as predictors of Cannabis dependence symptoms, problems, and craving: the mediating role of coping motives. J Stud Alcohol Drugs. 2016;77:889-97.

14. Goldman M, Suh JJ, Lynch KG, Szucs R, Ross J, Xie H, et al. Identifying risk factors for marijuana use among veterans affairs patients. J Addict Med. 2010;4:47-51.

15. Simons JS, Gaher RM, Correia CJ, Hansen CL, Christopher MS. An affectivemotivational model of marijuana and alcohol problems among college students. Psychol Addict Behav. 2005:19:326-34.

16. Baker TB, Piper ME, McCarthy DE, Majeskie MR, Fiore MC. Addiction motivation reformulated: an affective processing model of negative reinforcement. Psychol Rev. 2004;111:33-51.

17. Bonn-Miller MO, Boden MT, Bucossi MM, Babson KA. Self-reported cannabis use characteristics, patterns and helpfulness among medical cannabis users. Am J Drug Alcohol Abuse. 2014:40:23-30.

18. Swendsen JD, Tennen H, Carney MA, Affleck G, Willard A, Hromi A. Mood and alcohol consumption: an experience sampling test of the self-medication hypothesis. J Abnorm Psychol. 2000;109:198-204.

19. Martens MP, Neighbors C, Lewis MA, Lee CM, Oster-Aaland L, Larimer ME. The roles of negative affect and coping motives in the relationship between alcohol use and alcohol-related problems among college students. J Stud Alcohol Drugs. 2008:69:412-9.

20. Swendsen JD, Merikangas KR. The comorbidity of depression and substance use disorders. Clin Psychol Rev. 2000;20:173-89.

21. Bovasso GB. Cannabis abuse as a risk factor for depressive symptoms. Am J Psychiatry. 2001;158:2033-7.

22. Patton GC, Coffey C, Carlin JB, Degenhardt L, Lynskey M, Hall W. Cannabis use and mental health in young people: cohort study. Br Med J. 2002;325:1195-8.

23. Lev-Ran S, Roerecke M, Le Foll B, George TP, Mckenzie K, Rehm J. The association between cannabis use and depression: a systematic review and meta-analysis of longitudinal studies. Psychol Med. 2014;44:797-810.

24. Agosti V, Nunes E, Levin F. Rates of psychiatric comorbidity among U.S. residents with lifetime Cannabis dependence. Am J Drug Alcohol Abuse. 2002;28:643-52

25. Conway KP, Compton W, Stinson FES, Grant BF. Lifetime comorbidity of DSM-IV mood and anxiety disorders and specific drug use disorders: results from the National Epidemiologic Survey on alcohol and related conditions. J Clin PsychiatryJ Clin Psychiatry. 2006;6767:247-57.

26. Womack SR, Shaw DS, Weaver CM, Forbes EE. Bidirectional associations between cannabis use and depressive symptoms from adolescence through early adulthood among at-risk young men. J Stud Alcohol Drugs. 2016;77:287-97

27. De Wit H. Impulsivity as a determinant and consequence of drug use: a review of underlying processes. Addict Biol. 2009;14:22-31.

28. Dawe S, Loxton NJ. The role of impulsivity in the development of substance use and eating disorders. Neurosci Biobehav Rev. 2004;28:343-51.

29. Verdejo-Garclá A, Lawrence AJ, Clark L. Impulsivity as a vulnerability marker for substance-use disorders: review of findings from high-risk research, 
problem gamblers and genetic association studies. Neurosci Biobehav Rev. 2008;32:777-810

30. Aston ER, Metrik J, Amlung M, Kahler CW, Mackillop J. Interrelationships between marijuana demand and discounting of delayed rewards: convergence in behavioral economic methods. Drug Alcohol Depend. 2016; 169:141-7.

31. Johnson MW, Bickel WK, Baker F, Moore BA, Badger GJ, Budney AJ. Delay discounting in current and former marijuana-dependent individuals. Experimental and clinical psychopharmacology. 2010;18(1):99.

32. Day AM, Metrik J, Spillane NS, Kahler CW. Working memory and impulsivity predict marijuana-related problems among frequent users. Drug Alcohol Depend. 2013;131:171-4.

33. Bidwell LC, Metrik J, Mcgeary J, Palmer RHC, Francazio S, Knopik VS. Impulsivity, variation in the cannabinoid receptor (CNR1) and fatty acid amide hydrolase (FAAH) genes, and marijuana-related problems. J Stud Alcohol Drugs. 2013;74:867-78.

34. Lynam DR, Smith GT, Whiteside SP, Cyders MA. The UPPS-P: Assessing five personality pathways to impulsive behavior (technical report). West Lafayette: Purdue University; 2006

35. Smith GT, Fischer S, Cyders MA, Annus AM, Spillane NS, Mccarthy DM. On the validity and utility of discriminating among impulsivity-like traits. Assessment. 2007;14:155-70.

36. Whiteside SP, Lynam DR. The five factor model and impulsivity: using a structural model of personality to understand impulsivity. Pers Individ Dif. 2001;30:669-89.

37. Adams ZWZ, Kaiser AJ, Lynam DR, Charnigo RJ, Milich R. Drinking motives as mediators of the impulsivity-substance use relation: pathways for negative urgency, lack of premeditation, and sensation seeking. Addict Behav. 2012;37:848-55.

38. Derefinko K, Dewall CN, Metze AV, Walsh EC, Lynam DR. Do different facets of impulsivity predict different types of aggression? Aggress Behav. 2011;37: 223-33.

39. Birthrong A, Latzman RD. Aspects of impulsivity are differentially associated with risky sexual behaviors. Pers Individ Dif. 2014;57:8-13.

40. Cyders MA, Flory K, Rainer S, Smith GT. The role of personality dispositions to risky behavior in predicting first year college drinking. Addiction. 2009; 104:193-202.

41. Dvorak RD, Day AM. Marijuana and self-regulation: examining likelihood and intensity of use and problems. Addict Behav. 2014;39:709-12.

42. Kaiser AJ, Milich R, Lynam DR, Charnigo RJ. Negative urgency, distress tolerance, and substance abuse among college students. Addict Behav. 2012;37:1075-83.

43. Zapolski TCB, Cyders MA, Smith GT. Positive urgency predicts illegal drug use and risky sexual behavior. Psychol Addict Behav. 2009;23:348-54

44. Anestis MD, Selby EA, Joiner TE. The role of urgency in maladaptive behaviors. Behav Res Ther. 2007:45:3018-29.

45. Novak BK, Novak KD, Lynam DR, Foti D. Individual differences in the time course of reward processing: stage-specific links with depression and impulsivity. Biol Psychol. 2016;119:79-90

46. Robinson JM, Ladd BO, Anderson KG. When you see it, let it be: urgency, mindfulness and adolescent substance use. Addict Behav. 2014;39:1038-41.

47. Gonzalez VM, Reynolds B, Skewes MC. Role of impulsivity in the relationship between depression and alcohol problems among emerging adult college drinkers. Exp Clin Psychopharmacol. 2011;19:303-13.

48. American Psychiatric Association. Diagnostic and statistical manual of mental disorders (DSM-5॰). 2013.

49. FMB, Spitzer RL, Gibbon M, JBW W, First S, Gibbon W. Structured Clinical Interview for DSM-IV-TR Axis I Disorders, Research Version, Non-patient Edition (SCID-I/NP). New York: Biometrics Research, New York State Psychiatric Institute; 2002.

50. Stephens RS, Roffman RA, Curtin L. Comparison of extended versus brief treatments for marijuana use. J Consult Clin Psychol. 2000;68:898-908.

51. Peters EN, Nich C, Carroll KM. Primary outcomes in two randomized controlled trials of treatments for cannabis use disorders. Drug Alcohol Depend. 2011;118:408-16.

52. Dennis M, Funk R, Harrington Godley S, Godley MD, Waldron H. Crossvalidation of the alcohol and cannabis use measures in the global appraisal of individual needs (GAIN) and timeline Followback (TLFB; form 90) among adolescents in substance abuse treatment. Addiction. 2004;99:125-33.
53. Sobell L, Sobell M. Timeline follow-back: a technique for assessing selfreported alcohol consumption. In: Psychosocial and biological methods. Totowa, NJ: Humana Press; 1992. p. 41-72.

54. Cyders MA, Littlefield AK, Coffey S, Karyadi KA. Examination of a short English version of the UPPS-P impulsive behavior scale. Addict Behav. 2014; 39:1372-6.

55. Gunn RL, Smith GT. Risk factors for elementary school drinking: pubertal status, personality, and alcohol expectancies concurrently predict fifth grade alcohol consumption. Psychol Addict Behav. 2010;24:617-27.

56. Coskunpinar A, Dir AL, Cyders MA. Multidimensionality in impulsivity and alcohol use: a meta-analysis using the UPPS model of impulsivity. Alcohol Clin Exp Res. 2013;37:1441-50.

57. Arbuckle JL. Amos (Version 24.0). 2016.

58. Preacher KJ, Rucker DD, Hayes AF. Addressing moderated mediation hypotheses: theory, methods, and prescriptions. Multivariate Behav Res. 2007:42:185-227.

59. Bentler PM. Comparative fit indexes in structural models. Psychol Bull. 1990; 107:238-46.

60. Browne MW, Cudeck R. Alternative ways of assessing model fit. Sociol Methods Res. 1992;21:230-58.

61. Kline RB. Principles and practice of structural equation modeling. 2011.

62. Johnson KA, Bonn-Miller MO, Leyro TM, Zvolensky MJ. Anxious arousal and Anhedonic depression symptoms and the frequency of current marijuana use: testing the mediating role of marijuana-use coping motives among active users. J Stud Alcohol Drugs. 2009;70:543-50.

63. Buckner JD, Zvolensky MJ. Cannabis and related impairment: the unique roles of Cannabis use to cope with social anxiety and social avoidance. Am J Addict. 2014;23:598-603.

64. Bujarski SJ, Norberg MM, Copeland J. The association between distress tolerance and cannabis use-related problems: the mediating and moderating roles of coping motives and gender. Addict Behav. 2012;37: $1181-4$.

65. Wardell JD, Strang NM, Hendershot CS. Negative urgency mediates the relationship between childhood maltreatment and problems with alcohol and cannabis in late adolescence. Addict Behav. 2016;56:1-7.

66. Fischer S, Smith GT. Binge eating, problem drinking, and pathological gambling: linking behavior to shared traits and social learning. Pers Individ Dif. 2008;44:789-800

67. King KM, Karyadi KA, Luk JW, Patock-Peckham JA. Dispositions to rash action moderate the associations between concurrent drinking, depressive symptoms, and alcohol problems during emerging adulthood. Psychol Addict Behav. 2011;25:446-54.

68. Magid V, Colder CR. The UPPS impulsive behavior scale: factor structure and associations with college drinking. Pers Individ Dif. 2007;43:1927-37.

69. Kessler RC, Chiu WT, Demler O, Walters EE. Prevalence, severity, and comorbidity of 12-month DSM-IV disorders in the National Comorbidity Survey Replication. Arch Gen Psychiatry. 2005;62:617-27.

70. Kessler RC, Heeringa SG, Stein MB, Colpe LJ, Fullerton CS, Hwang I, et al. Thirty-day prevalence of DSM-IV mental disorders among nondeployed soldiers in the US Army. JAMA Psychiatry. 2014:71:504.

71. Searles JS, Helzer JE, Rose GL, Badger GJ. Concurrent and retrospective reports of alcohol consumption across 30, 90 and 366 days: interactive voice response compared with the timeline follow back. J Stud Alcohol. 2002;63:352-62.

72. Carey KB. Reliability and validity of the time-line follow-back interview among psychiatric outpatients: a preliminary report. Psychol Addict Behav. 1997;11:26-33. 